\title{
Engaging on gerodontology with the platform for better oral health in Europe
}

The platform for better oral health in Europe is a joint initiative of the Association for Dental Education in Europe (ADEE), the Council of European Chief Dental Officers (CECDO), the European Association of Dental Public Health (EADPH) and the European Dental Health Foundation (EDHF). The platform is made up of five core member organisations and thirteen associate members, including the European College of Gerodontology. Now under the leadership of Dr. Georgios Taskos, the goal of the platform is to create a common European approach towards improved oral health education, promotion, and access to care in Europe (http://www.oralhealthplatform.eu).

The associate members of the platform meet on a yearly basis in Brussels where the European College of Gerodontology is represented by its past President Dr. Gerry McKenna. The role of the platform has evolved in recent times and it has refocused its strategy towards lobbying for the inclusion of oral health indicators in the next iteration of the EU/ OECD Health at a Glance report. This report collates a vast range of health data across Europe, but cur-

\section{Dr. Gerry McKenna}

Past President, European College of Gerodontology

Senior Lecturer / Consultant in Restorative Dentistry

Centre for Public Health

Queen's University Belfast

Belfast BT7 1NN, UK rently does not include any oral health statistics. The platform's secretariat has made good progress on this front, after a series of meetings with DG SANTE officials.

The second key focus for the platform remains the collection of best practices in oral health. However, now there is more focus on aligning these initiatives with those already underway at the EU Commission level. The platform is currently drafting up a set of criteria which will be used to assess each best practice and how it matches the output from the Joint Action on Chronic Diseases (CHRODIS). The Platform remains supportive of suitable examples focused on older adults and from the European College of Gerodontology.

Engaging with the platform for better oral health in Europe remains an important focus for the European College of Gerodontology. The platform provides an avenue for meaningful engagement with European policymakers in order to ensure that the oral health of older people is prioritized. 